\title{
Moral Messaging in a Time of COVID-19
}

\section{THIS IS A PREPRINT}

The manuscript has not yet been peer-reviewed.

\author{
Michal Misiak $^{1,2, *}$; Oliver Scott Curry²; Petr Tureček ${ }^{3,4}$
}

\begin{abstract}
1. Institute of Psychology, University of Wroclaw, Poland
2. School of Anthropology \& Museum Ethnography, University of Oxford, United Kingdom

3. Department of Philosophy and History of Science, Charles University, Czech Republic

4. Center for Theoretical Study, Charles University and Czech Academy of Sciences, Czech Republic
\end{abstract}

\section{Author Note}

The study was pre-registered (osf.io/4tzub).

All data and code can be accessed online (osf.io/fr5ed/).

We have no conflict of interest to disclose.

Acknowledgements: Michal Misiak was supported by the scholarship of the Polish National Science Centre (2020/36/T/HS6/00256).

Corresponding Author: Michal Misiak, Institute of Psychology, University of Wroclaw, ul. Dawida 1, 50-527 Wroclaw, Poland; +48 7136720 01; e-mail: michal.misiak@uwr.edu.pl 


\begin{abstract}
Do appeals to moral values increase compliance with COVID-19 public health measures? According to the theory of 'Morality as cooperation', morality consists of a collection of cooperative principles that help us get along, work together and promote the common good. We experimentally investigated whether messages that appeal to these moral principles increase pandemic-related public health behaviour. We investigated: (a) Are moral messages more effective than non-moral messages? (b) Are some moral messages more effective than others? c) Is the effectiveness of moral messages dependant on the corresponding moral values of the individual? (d) Do these effects hold across cultures? Participants (recruited from the USA and India) were presented with one of ten messages, asked questions about their intentions to follow the restrictions, were asked to donate to a charity fighting COVID-19, and completed the Morality-as-Cooperation Relevance Questionnaire.
\end{abstract}

We found that: (a) Moral messages were more effective in increasing the donation than a non-moral message and more effective in increasing the intentions to act prosocially than a lack of message. (b) Messages appealing to heroism increased the intentions to act prosocially in both samples. (c) The effectiveness of moral messages was better when they were concordant with participants' moral values, but only in the USA sample. (d) We also found that some moral messages were effective only in a particular population. Thus, moral messages may increase compliance with public health guidelines, but it is necessary to appeal to particular values and to tailor these messages for a specific culture.

Keywords: COVID-19, pandemic, morality, Morality as cooperation, moral messaging, persuasion 


\section{Moral Messaging in a Time of COVID-19}

The COVID-19 outbreak rapidly spread throughout the world contributing to the death of millions of people worldwide (World Health Organization, 2021). To slow down virus transmission, governments have imposed a variety of restrictions and guidelines (Kenyon, 2020). Following the restrictions, however, requires that we all work together helping our family, friends and neighbours, making sacrifices, following health authorities, and sharing the burdens of the disease equitably - for the greater good. So how to persuade people to accept the necessary restrictions and follow the guidelines?

Since by complying with restrictions we care not only for our own health but also for the health of others, one option is to emphasize that complying with restrictions is morally good behaviour. It has already been shown that more prosocial individuals are more likely to engage in health behaviours during the COVID-19 pandemic (Campos-Mercade et al., 2021) and there is some evidence showing that prosocial messages are effective at increasing intentions to engage in preventive behaviours such as wearing a face mask and practising social distancing (Capraro \& Barcelo, 2020; Lunn et al., 2020; Pfattheicher et al., 2020).

However, recent research suggests there is not just one moral value, there are many. It is possible that moral messages that appeal to a wide range of moral values, or that target the most relevant moral values, might be more effective in mobilising the public.

According to the theory of Morality as Cooperation (MAC), morality is a collection of cooperative rules (Curry, 2016). Cooperation is immensely valuable; hence we value it immensely, and we call these values 'moral'. The theory also predicts that, because there are many types of cooperation, there will be many types of morality/moral values, including Family, Loyalty, Reciprocity, Heroism, Deference, Fairness, and Property. Briefly, Family refers to the obligation to love and care for family members, especially children. Loyalty refers to the obligation to pursue projects of mutual interest with others and to provide 
preferential help to members of the resulting groups (for example clubs, coalitions, communities). Reciprocity refers to the obligation to return favours (and punish those who don't). Heroism refers to the (supererogatory) obligation to display costly signals of power, status and prestige, such as bravery and generosity. Deference refers to the obligation to show respect to powerful, prestigious, heroic individuals. Fairness refers to the obligation to divide disputed resources, rather than trying to monopolise them. And Property refers to the obligation to respect prior possession of resources and refrain from theft.

Previous research suggests that these seven types of morality are evolutionarily ancient (Curry, 2016), genetically-based (Zakharin et al., in prep.), early-developing (Dawkins et al., 2020)., psychometrically-distinct (Curry, Jones Chesters, et al., 2019), and cross-culturally universal (Curry, Mullins, et al., 2019). Research has also shown that people who endorse the values of Family, Loyalty, Reciprocity, Heroism, Deference, and Property are more likely to endorse policies limiting physical distancing (Boggio, et al., in prep.).

It follows that appeals to the specific moral values identified by Morality-asCooperation might better catalyse cooperative dispositions and persuade more people to 'do the right thing' and follow COVID-19 related public health guidelines. Previous research has shown that well-designed messages can change peoples' behaviour (Armanasco et al., 2017), including health behaviours (Gallagher \& Updegraff, 2012), environmental practices (Gifford \& Comeau, 2011), and dietary choices (Elbert \& Ots, 2018; Palomo-Vélez et al., 2018). Does appealing to specific moral principles make people change their behaviour in the face of the pandemic?

\section{Current Study}

The present study investigates four main questions: a) Are MAC moral messages more effective than non-moral messages? b) Are any MAC moral messages more effective than others? c) Does the effectiveness of MAC moral messages depend on (are they mediated 
by) the corresponding moral values of the participant? and d) Do these effects hold across cultures? To answer these questions, we preregistered ${ }^{1}$ and conducted an experimental study in which we presented people with a variety of health messages and gathered data on their pandemic-related behavioural intentions, willingness to donate to a charity fighting the consequences of the pandemic, and their moral values. Our sample consisted of participants from the USA (data gathered in April 2020) and from India (data gathered in May 2020).

\section{Methods}

Participants were recruited via qualtrics.com. Our final sample consisted of 313 participants from USA (156 men, 157 women, mean age $=45.96, \mathrm{SD}=16.70$, range $=18$ 80) and 302 participants from India (154 men, 148 women, mean age $=42.69, \mathrm{SD}=15.70$, range $=18-80) .{ }^{2}$ They were first asked about their age, gender, and the perceived threat of COVID-19 to their health. Next, they were presented with one of ten health messages and asked questions about their behavioural intentions regarding social distancing (block 1). After that, they completed the Morality as Cooperation Questionnaire (block 2; we presented these two blocks randomly, to minimise order effects.) Finally, the participants were asked whether they would donate part of their fee to a COVID related charity. The study was approved by the institutional review board.

\footnotetext{
${ }^{1}$ The pre-registration was updated as we substantially changed our initial plan. We started conducting the study according to the early pre-registration (https://osf.io/qrjxe). We noticed, however, that the measure aimed at estimating the intention to cooperate during the pandemic reached a ceiling effect (most of the participants declared an extraordinarily strong intention to cooperate). Also, we were not able to recruit our participants at a sufficient rate to observe the effect of time on the change of intentions to cooperate. Our pre-registration was updated (https://osf.io/4tzub). We decided to expand the intentions scale and to avoid the ceiling effect, we reformulated the cooperative behaviours to be more challenging. Additionally, we dropped the time variable and included a behavioural variable-a donation. The sample consisted of USA and India citizens, instead of the citizens of Poland.

${ }^{2}$ We collected responses from 627 participants in total. A few respondents in the Indian sample, however, reported to be over 100 years old, while the oldest US participant reported to be 82 years of age. We have decided to discard all participants above the age 80 to work with two samples with comparable age range (the results are, however, virtually identical if we retain full samples regardless of participants 'age). All responses took more than 240 seconds, which was set as a reasonable minimal threshold for honest questionnaire completion and all participants indicated an exact middle point in the attention check question.
} 


\section{Experimental Manipulation}

To test the effect of moral messages on health intentions and donation behaviour, we prepared a set of seven messages that appealed to MAC moral principles: Family, Group, Reciprocity, Heroism, Deference, Fairness, Property. We also prepared three categories of control messages: Blank, Prudence, and General Moral. To increase the participants' attention, we asked them to rate the clarity of the message on a 100-point scale. Each message began with an excerpt based on the WHO briefing on COVID-19 (World Health Organization, 2020). The second part of the message was based on one of the seven MAC moral principles, general morality, prudence or was absent. All the messages used in the study are presented in Table 1.

\section{Table 1}

The list of moral and control messages persuading to follow social distancing used in the study

The first part of the message

Please read the following information carefully:

According to the World Health Organization, the COVID-19 outbreak can now be described as a pandemic. This assessment reflects the speed and the scale of transmission. Despite frequent warnings, the World Health Organization is deeply concerned that people are not taking the necessary steps to combat this serious threat.

The second part of the message

Type of message

Message

People who follow the guidelines and take precautions are being loving. You

Family

Morality as

Cooperation

messages have a special obligation to help your family. People who DO NOT follow the guidelines and take precautions are being uncaring. They are putting their families at risk.

People who follow the guidelines and take precautions are being civic-minded.

Group We are all in this together and have to stand strong. People who DO NOT follow the guidelines and take precautions are being unpatriotic. They are putting their community at risk. 


\begin{tabular}{|c|c|c|}
\hline & Reciprocity & $\begin{array}{l}\text { People who follow the guidelines and take precautions are being trustworthy. } \\
\text { You help others, and they will help you. People who DO NOT follow the } \\
\text { guidelines and take precautions are being untrustworthy / cheats. They are } \\
\text { harming others who are helping them. }\end{array}$ \\
\hline & Heroism & $\begin{array}{l}\text { People who follow the guidelines and take precautions are being brave. The } \\
\text { strong have a duty to protect the weak. People who DO NOT follow the } \\
\text { guidelines and take precautions are being cowardly. Their weakness is putting } \\
\text { others at risk. }\end{array}$ \\
\hline & Deference & $\begin{array}{l}\text { People who follow the guidelines and take precautions are being respectful. } \\
\text { We ought to follow the advice of those in authority. People who DO NOT } \\
\text { follow the guidelines and take precautions are being hubristic. Their } \\
\text { disobedience puts others at risk. }\end{array}$ \\
\hline & Fairness & $\begin{array}{l}\text { People who follow the guidelines and take precautions are being fair. We all } \\
\text { have to equally share the burdens of solving this problem. People who DO } \\
\text { NOT follow the guidelines and take precautions are being unfair. They are } \\
\text { expecting others to do all the work to solve this problem. }\end{array}$ \\
\hline & Property & $\begin{array}{l}\text { People who follow the guidelines and take precautions are being mindful of } \\
\text { others' space. We have no right to infringe upon the health of others. People } \\
\text { who DO NOT follow the guidelines and take precautions are being like } \\
\text { thieves. They are robbing others of their health. }\end{array}$ \\
\hline \multirow{3}{*}{$\begin{array}{l}\text { Control } \\
\text { messages }\end{array}$} & Blank & - \\
\hline & Prudence & $\begin{array}{l}\text { People who follow the guidelines and take precautions are being sensible. You } \\
\text { have to do what you can to help yourself. People who DO NOT follow the } \\
\text { guidelines and take precautions are being foolish. They are putting themselves } \\
\text { at unnecessary risk. }\end{array}$ \\
\hline & $\begin{array}{l}\text { General } \\
\text { moral }\end{array}$ & $\begin{array}{l}\text { People who follow the guidelines and take precautions are being ethical. You } \\
\text { have to do what you can to help others. People who DO NOT follow the } \\
\text { guidelines and take precautions are being bad. They are putting others at } \\
\text { unnecessary risk. }\end{array}$ \\
\hline
\end{tabular}




\section{Behavioural intentions regarding social distancing}

To assess peoples' intentions during the pandemic, we developed a short scale, which listed a set of intentions that reflected potential health-related behaviours. In our pilot analyses, we found out that the scale has two underlying factors: precautious intentions and prosocial intentions (Table 2).

\section{Table 2}

Scale for measuring the intentions to cooperate during the pandemics

Factor Item

1. I will try to avoid direct contact with every person possible.

2. If I notice any symptoms of the coronavirus disease, I plan to voluntarily quarantine myself for at least 14 days.

3. I plan to stay home and leave it only in the case of an emergency or to supply the food Precautious shortage.

4. I will wash my hands with soap for at least 30 seconds every time I touch anything that could potentially transmit the virus.

5. I will cancel all my upcoming vacations, including those I've already paid for, even if it would be legally possible to travel.

6. I will help my neighbours with grocery shopping if they ask me.

7. I will not hoard food, medicine, or other products.

Prosocial

8. I will take care of my neighbour's children if they have to be hospitalised due to the virus.

9. I plan to financially support small local companies that struggle to survive through the epidemic. 


\section{MAC-Q Relevance scale}

To assess the moral values we used the MAC-Q Relevance Scale (Curry, Jones Chesters, et al., 2019), which asks how relevant various factors are to making moral decisions. People were asked to rate 21 different behaviours on a 100-point scale, from 1-not at all relevant, to 100-extremely relevant. Sample items include Family: Whether or not someone helped a member of their family; Group cooperation: Whether or not someone acted in a way that helped their community; and Heroism: Whether or not someone was brave.

\section{Donation}

The participants were also entered into a lottery where they could win $\$ 100$, and given the option of donating a portion of their winnings (0-100\%) to the Emergency Respond Fund, organised by the CDC (CDC Foundation, 2021).

\section{Data analysis}

Firstly, we employed the confirmatory factor analysis (CFA) to evaluate the applicability of the two-factor structure yielded by previous exploratory factor analysis (EFA) on the incomplete USA sample. Then, to assess the effect of the messages, we created a structural Bayesian model, with separate index intercepts for each priming message, and slopes for the corresponding MAC score, predicting precaution and prosocial intentions, and the donation, with MAC dimensions as mediators between demographic variables (gender and age) and the outcomes. The statistical model represented as a set of equations can be found in Supplementary material S1 and the graphical representation of the model in Supplementary material Figure S1. The complete structural model without factor loadings was parametrised by 103 numbers that were estimated in a single joint posterior distribution using MCMC sampling method. We collected approximately 3 observations per parameter estimate. Our desired sample size was therefore 300 participants from each country. 
All MAC dimensions, latent factors, donation, self-reported perceived COVID danger for the participant, and age were standardised prior to the analysis (mean $=0, \mathrm{SD}=1$ ) to allow for an easy choice of prior parameter distributions, and posterior distributions are reported as such for straightforward comparison between effect sizes in multiple linear regressions that constituted the model. Unbiased, regularised priors were used for all intercepts and slopes in the analysis. Posterior distributions of likely values of model parameters are reported as a result of the analysis.

We analysed both national samples together and yielded a common posterior distribution of parameter estimates. We compared the model with an enhanced model that contrasted the USA and Indian samples above the common parameter estimates. This model was extended by an additional set of 92 parameters; one contrast between US and Indian samples per parameter except for standard deviations of the data dispersion around predicted values. Each contrast was assigned a regularized normal prior distribution with mean $=0$ and $\mathrm{SD}=0.2$. We compared these models using Widely Applicable Information Criterion (WAIC). We also evaluated the structural model on both national samples separately with results equivalent to the model with a contrast between national samples. Complete posterior distributions including contrasts and national samples can be found in the Supplementary materials S2-S3. All data and code can be accessed online (https://osf.io/fr5ed/).

\section{Results}

The CFA analysis confirmed the structures of Precautious and Prosocial intentions. Measures RMSEA (USA: 0.08, India: 0.10, together: 0.07) and CFI (USA: 0.93, India: 0.95, together: 0.96) indicate a good model fit. Parallel analysis suggested 2 underlying factors in both samples which were extracted using EFA with oblimin rotation to allow for correlation between the factors. Factor loadings were similar in both samples (see Figure 1) and the 
factors were correlated more in the Indian $(r=0.65)$ than the complete USA sample $(r=$ $0.18)$.

\section{Figure 1}

Results of the exploratory factor analysis with oblimin rotation in the US $(N=313)$ and Indian $(N=302)$ sample revealing consistently 2 underlying factors predicting 9 items of motivation to minimise infection spread

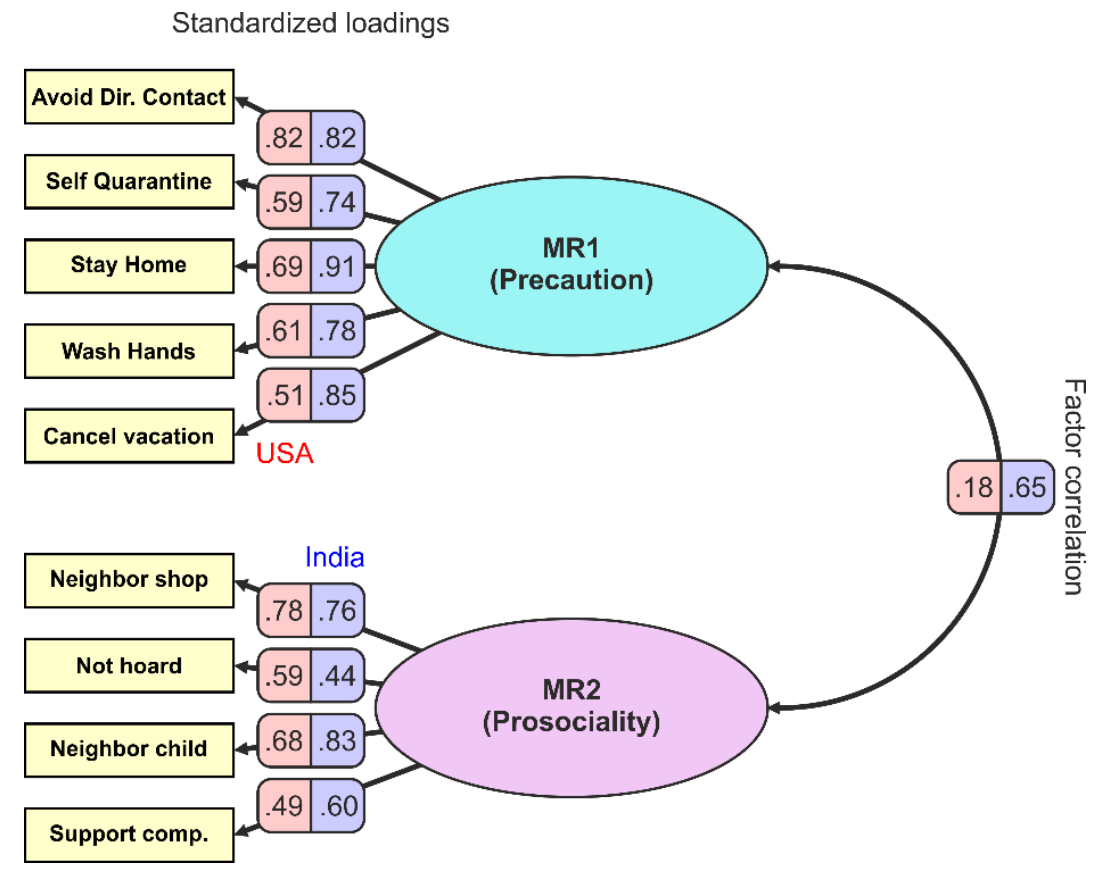

People in both countries were willing to donate similarly (USA mean $=51.43, \mathrm{SD}=$ 35.75 , range $=0-100$, Indian mean $=50.39, \mathrm{SD}=31.22$, range $=0-100)$. Higher score of prosociality seems to elevate the donation slightly in both samples $[\beta=0.07,89 \%$ CI: -0.00 , $0.14, \beta \_$US $=0.07,89 \%$ CI: $-0.03,0.17, \beta \_$In $=0.11,89 \%$ CI: $\left.-0.01,0.23\right]$.

Models comparison, according to WAIC, favoured the parsimonious single sample model $(\mathrm{WAIC}=1743.6, \mathrm{SE}=24.75)$ over the varying intercept model with contrast estimates $(\mathrm{WAIC}=1759.2, \mathrm{SE}=25.27$, relative weights sided with the single sample model 1:0) in the full model predicting donation, and in the partial model Prosocial intentions 
$\left(\mathrm{WAIC} \_\right.$single $=1611.4, \mathrm{SE}=46.43, \mathrm{WAIC}$ _contrast $=1614.0, \mathrm{SE}=46.97$, weights $=$ 0.79:0.21), but sided with the partial model contrasting India and USA above the common estimate in the prediction of Precautious intentions (WAIC_single $=1536.2, \mathrm{SE}=62.25$, WAIC_contrast $=1524.8, \mathrm{SE}=60.51$, weights $=0: 1)$. In all three comparisons, standard errors were much larger than the difference between WAICs of the compare models.

\section{Do moral messages have a greater effect on intentions and behaviour than non-moral} messages?

Moral messages induced higher donation than the Prudence message $[\delta=0.22,89 \%$ CI: $0.04,0.40]$, but not much more than the condition without any message $[\delta=0.10,89 \%$ CI: -0.08, 0.28]. Moral messages did not increase Precautious intentions in comparison to Prudence message $[\delta=-0.10,89 \% \mathrm{CI}:-0.27,0.06]$ or absence of a message $[\delta=-0.08,89 \%$ CI: $-0.23,0.08]$. They also did not increase the Prosocial intentions in comparison to Prudence message [ $\delta=-0.03,89 \%$ CI: $-0.20,0.14]$. However, in comparison to the absence of a message, moral messages increased Prosocial intentions [ $\delta=0.13,89 \%$ CI: -0.03 , 0.29] — this estimate was likely driven by a large impact of Heroism message (see below).

\section{Do some moral messages have a greater effect on intentions and behaviour than others?}

We found out that Heroism messages positively increased Prosocial intentions in both samples $[\beta=0.24,89 \% \mathrm{CI}: 0.07,0.41]$. At the same time Heroism, messages had a negative impact on the Precautious intentions $[\beta=-0.12,89 \%$ CI: $-0.28,0.05]$. We also found that displaying a Prudential message decreased the amount of donated money $[\beta=-0.19,89 \% \mathrm{CI}$ : $-0.38,-0.01]$

\section{Are these effects mediated by moral values?}

Descriptive statistics for the results of the MAC-Q scale for each sample are presented in Table 4. The effect of the MAC score concordant with the message increased the Precautious intentions in the US sample [ $\beta_{U S}=0.14,89 \%$ CI: $\left.0.00,0.27\right]$, but the overall 
effect does not hold $[\beta=0.00,89 \%$ CI: $-0.09,0.09]$ due to its absence in the Indian sample $\left[\beta_{\text {In }}=-0.06,89 \% \mathrm{CI}:-0.18,0.05\right]$.

Table 4

Descriptive statistics for MAC-Q relevance scale scores

\begin{tabular}{lcccccccc}
\hline & \multicolumn{2}{c}{ USA sample } & & \multicolumn{2}{c}{ Indian sample } & & \multicolumn{2}{c}{ Total sample } \\
\cline { 2 - 3 } \cline { 8 - 9 } MAC category & $\mathrm{M}$ & $\mathrm{SD}$ & & $\mathrm{M}$ & $\mathrm{SD}$ & & $\mathrm{M}$ & $\mathrm{SD}$ \\
\hline Family & 80.2 & 17.1 & & 78.2 & 21.2 & & 79.2 & 19.2 \\
Group & 73.9 & 19.6 & & 75.8 & 21.5 & & 74.9 & 20.6 \\
Reciprocity & 78.6 & 18.5 & & 74.7 & 21.2 & & 76.7 & 20.0 \\
Heroism & 71.2 & 20.9 & & 69.6 & 21.6 & & 70.4 & 21.2 \\
Deference & 66.4 & 21.2 & & 61.6 & 20.8 & & 64.0 & 21.1 \\
Fairness & 64.4 & 24.2 & & 59.3 & 24.4 & & 61.9 & 24.4 \\
Property & 67.7 & 26.8 & & 50.2 & 30.9 & & 59.1 & 30.1 \\
\hline
\end{tabular}

\section{Do these effects vary across cultures?}

We found some effects of messages specific to the USA sample. Messages referring to Reciprocity elevated intentions to act precautiously $\left[\beta_{U S}=0.18,89 \% \mathrm{CI}:-0.03,0.38\right]$. Conversely, messages referring to Deference decreased the intentions to act precautiously $\left[\beta_{U S}=-0.27,89 \% \mathrm{CI}:-0.48,-0.05\right]$. Also, messages referring to Property decreased the amount of donated money $\left[\beta_{U S}=-0.14,89 \% \mathrm{CI}:-0.37,0.09\right]$.

We also found that the control condition that lacked the second part of the message decreased the amount of donated money in the Indian sample $\left[\beta_{\text {In }}=-0.16,89 \%\right.$ CI: -0.39 , 0.06]. The effects of messages on Precautious intentions, Prosocial intentions and donation are presented in Figure 2. 


\section{Figure 2}

Posterior distribution of parameter values in the part of the structural model that predicts donation,

Precautious intentions, and Prosocial intentions

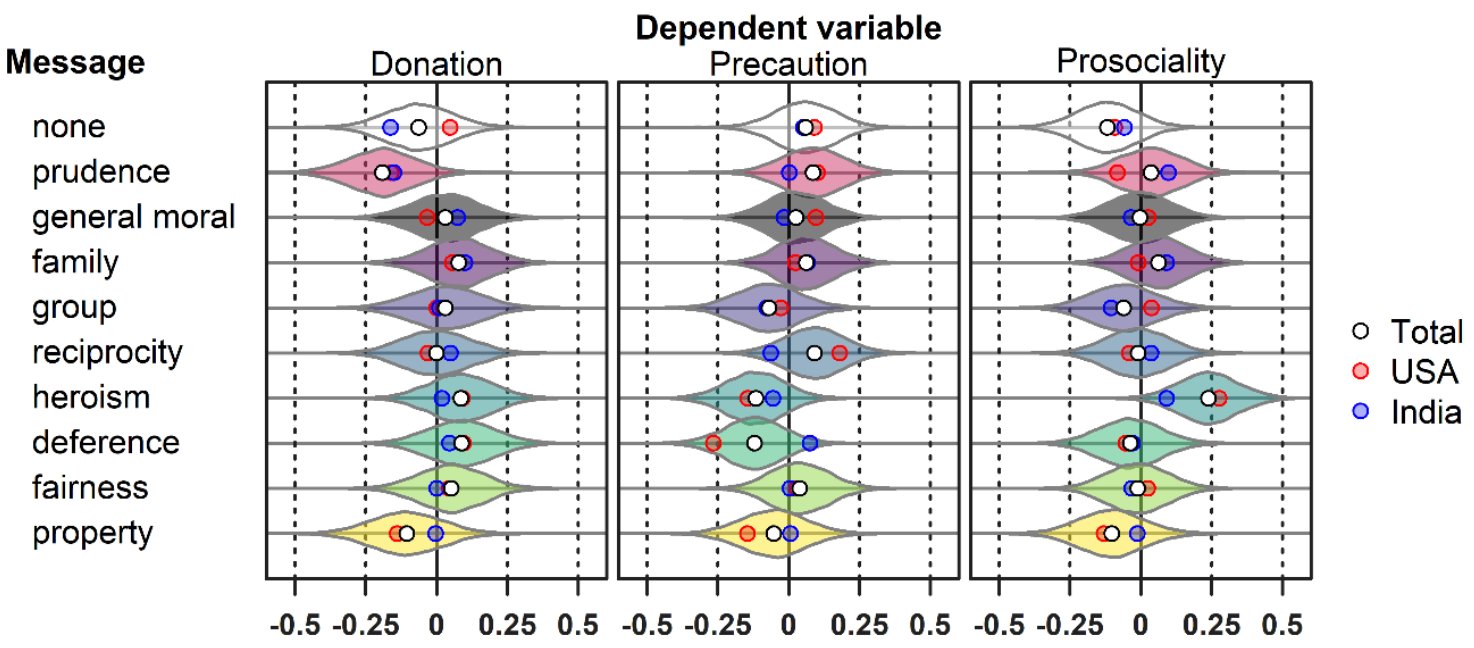

Note. Density diamonds outline distributions of plausible parameter values in the model without contrasts between national samples. White points mark means of these distributions and coloured points mark distribution means estimated separately for each national sample.

\section{Exploratory analyses}

The results of additional analyses, which explored the associations between MAC-Q scores, demographic factors, Precautious intentions and Prosocial intentions as well as donation are presented in the Supplementary material (S4).

\section{Discussion}

The present study investigated the effects of moral messages, based on the Moralityas-cooperation framework, on people's pandemic-related intentions and behaviours. We aimed at verifying (1) whether moral messages are more effective than non-moral messages, (2) whether some moral messages are more effective than other types of moral messages, (3) whether the effectiveness of moral messages are mediated by the corresponding moral values of the individual, and (4) whether these effects hold across cultures.

Regarding the first question, we found that, compared to non-moral messages, moral messages increased peoples' donations to a fund aimed at fighting COVID-19, and compared 
to a lack of message, moral messages increased people's intentions to act prosocially.

Regarding the second question, we found that the only category of moral messages that had an effect in both samples was the category of Heroism - messages referring to these values increased people's prosocial intentions, but at the same time, decreased peoples' precautious intentions. Also, displaying Prudential (non-moral) messages decreased the amount of donated money. Regarding the third question, we found that messages concordant with people's own moral values increased their precautious intentions, but only in the US sample. Finally, regarding the fourth question, we found differences between the US sample and the Indian sample in their reactions to particular moral messages, including backfiring effects. In the US sample, Reciprocity messages increased the intentions to act precautiously, Deference messages decreased the intentions to act precautiously and Property messages decreased the amount of donated money. In the Indian sample, we found that the lack of a message decreased the amount of donated money.

When compared to non-moral (Prudential) message, moral messages increased peoples' donations to a fund aimed at fighting COVID-19, and compared to a lack of message, moral messages increased people's intentions to act prosocially. This result supports our hypothesis only partially — it suggests that references to morality may generally have some effect, but it is not clear why these differences were observed only in these particular comparisons. However, the results get clearer when we look at specific conditions.

Heroism was the only type of moral category that had a similar effect in both samples. Message capitalizing on Heroism values emphasized that people who follow the health guidelines are being brave, that the strong must protect the weak and that those who do not follow guidelines are being cowardly and are putting others at risk. On the one hand, people increased their intentions to act prosocially in response to the Heroism-based message (e.g., taking care of neighbour's children if they must be hospitalised due to the virus), but on 
the other hand, they decreased their intentions to act precautiously (e.g., washing hands with soap for at least 30 seconds). Both of these effects reflect one of the fundamental aspects of the Heroism category-heroic (hawkish) behaviours act as signals of superior power and status (Curry, 2007). They benefit others, but at the same time, they are risky, and costly (Kraft-Todd \& Rand, 2019). Similarly, prosocial behaviours during the pandemic certainly benefit others, might be risky and costly. Precautious behaviours, contrarily, are focused on securing one's own health, therefore might be interpreted as selfish and cowardly. It could be that messages glorifying heroism triggered the intention for risky, or costly behaviours and at the same time suppressed the intention for behaviours that could be interpreted as a sign of weakness, as they focused on preserving one's own health. This result demonstrates that some moral messages may have a backfiring effect - this effect is already known in the literature, e.g., on vaccine hesitancy (Nyhan et al., 2014).

Tailoring persuasive messages in accordance with peoples' personal moral values also might be a valid approach, but only in a certain type of culture. People who received messages concordant with their moral values increased their intentions to act precautiouslyhowever, this effect was found only in the US sample. It could be that this populational difference was due to the cultural differences between Indian and US populations associated with the "tightness" and "looseness" of behavioural norms (Gelfand et al., 2011). Tight cultures, such as Indian, developed strong behavioural norms that they adhere to and are more likely to restrict the range of permissible behaviours. Whereas loose cultures, such as the USA, have a much lower need for order and are more permissible toward deviant behaviours. It could be that messages referring to peoples' personal moral values had a better effect on their intentions in the 'loose' culture, as it is more permissible to realise personal motivations, rather than motivations that align with the group interest. This finding is in line with the recent observation that the link between personal values and behaviour is much more 
prominent in loose cultures, as in these cultures people are less restricted by social norms and are more likely to be driven by their personal norms (Elster \& Gelfand, 2021).

We observed populational differences regarding particular moral messages as well. Reciprocity increased the intentions to act precautiously in the United States sample. It may be because compliance with health precautions was voluntary in the USA, and people's behaviour may have been more dependent on what others were doing; whereas in India compliance was mandatory by law (on March 24, the Indian government imposed a nationwide lockdown (Sarkar et al., 2020; Trivedi, 2020). It could be that people in India did not interpret behaviours preventing COVID-19 as favours to others, but rather as behaviours aimed at avoiding legal costs.

We also found backfiring effects in the United States. Messages emphasising deference to authority decreased peoples' intentions to act precautiously. Perhaps, the importance of 'freedom' in the USA led people to react negatively to these messages, whereas deference is crucial to Hindu culture, which stresses the importance of the concepts like dharma. Indeed, DeFranza and colleagues (2020) demonstrated that restricting social gatherings during the pandemic could result in reactance and an increase in social gatherings. Consistent with previous work, showing differences in tightness-looseness in the US and India (Gelfand et al., 2011), respecting authority is more critical for the citizens of India than for the citizens of the United States (Khan \& Stagnaro, 2015). Finally, we found that people donated less money when they received a Property-based message (US) and when they did not receive any message at all (India). It might be that people from a more individualistic population, the USA, see possessions as part of their own self (Morrison \& Johnson, 2011), therefore framing a moral message in the context of possessions could increase individualists perceived value of their money and discourage them from donating. In India, however, any type of message had a positive effect on donation. 
Differences between USA and Indian samples, and our post-hoc explanations, should be treated with caution. We demonstrated that some population-level factors influence peoples' response to COVID-19 moral messages, but we do not know whether these factors are associated with culture, or circumstances associated with the pandemic, like the response strategy employed by each government. Nevertheless, we want to stress that population differences might be crucial in using moral messaging to change behaviours limiting the spread of the virus - especially because they can have a backfiring effect.

\section{Limitations and Future Directions}

It is important to interpret our results with caution. Our sample included participants from two populations and it does not allow us to extrapolate the results on a wider group of people. Furthermore, we conducted our study concerning peoples' intentions and behaviours during the COVID-19 pandemic. We do not know to what extent the results would apply to different situations and different kinds of behaviours. Finally, our messages appealed to both positive and negative versions of the same moral ('by following health guidelines you are acting morally' and 'by breaking health guidelines you are acting immorally'). As such, we don't know whether different forms of the message, to different morals, might be more effective. It has been shown recently, for example, that negative messages regarding social distancing increased peoples' defiance (Legate et al., 2021).

We believe that our results might inform future studies regarding other health behaviours associated with the current COVID-19 pandemic, like vaccination. It has been demonstrated that vaccine hesitancy might be associated with moral values (Amin et al., 2017) and that a carefully designed communication strategy is an important aspect of whether people will vaccinate (Nyhan et al., 2014). Recent studies exploring social determinants of COVID-19 vaccine hesitancy have argued that peoples' social attitudes might lead to a delay in the vaccination process and future studies should investigate how to design effective 
communication (Soral \& Bilewicz, 2021). We propose that Morality-as-cooperation delivers a useful conceptual framework for designing persuasive messages - it can also allow for controlling backfiring effects of such messages.

\section{Conclusion}

The present study investigated the role of a wide range of morals on behaviour in the pandemic. The findings highlight the utility of adopting MAC's comprehensive account of moral values in messaging. We found that messages referring to Heroism increased people's intentions to act prosocially both in US and Indian samples. In addition, we found that other messages didn't uniformly change people's behaviour, and some of them backfired. Future work should build on this, to better understand the role of moral values in real-world behaviour. 


\section{REFERENCES}

Amin, A. B., Bednarczyk, R. A., Ray, C. E., Melchiori, K. J., Graham, J., Huntsinger, J. R., \& Omer, S. B. (2017). Association of moral values with vaccine hesitancy. Nature Human Behaviour, 1(12), 873-880.

Armanasco, A. A., Miller, Y. D., Fjeldsoe, B. S., \& Marshall, A. L. (2017). Preventive health behavior change text message interventions: A meta-analysis. American Journal of Preventive Medicine, 52(3), 391-402.

Boggio, P. S., Nezlek, J. B., Alfano, M., Azevedo, F., Capraro, V., Cichocka, A., Parnaments, P., Geudencio Rego, G., Sampaio, W., Sjåstad, H., Van Bavel, J., (in preparation). The pandemic is a time for moral actions: Morality predicts support for collective action to fight the pandemic in an international sample.

Campos-Mercade, P., Meier, A. N., Schneider, F. H., \& Wengström, E. (2021). Prosociality predicts health behaviors during the COVID-19 pandemic. Journal of public economics, 195, 104367.

Capraro, V., \& Barcelo, H. (2020). The effect of messaging and gender on intentions to wear a face covering to slow down COVID-19 transmission. Journal of Behavioral Economics for Policy, 4(S2), 45-55.

CDC Foundation (2021). Responding to Coronavirus.

https://www.cdcfoundation.org/coronavirus

Curry, O. S. (2007). The Conflict-Resolution Theory of Virtue. In W. Sinnott-Armstrong, Moral Psychology: The Evolution of Morality: Adaptations and Innateness (Vol. 1, pp. 251-261). MIT Press.

Curry, O. S. (2016). Morality as Cooperation: A Problem-Centred Approach. In T. K. Shackelford \& R. D. Hansen (Eds.), The Evolution of Morality (pp. 27-51). Springer International Publishing. 
Curry, O. S., Jones Chesters, M., \& Van Lissa, C. J. (2019). Mapping morality with a compass: Testing the theory of 'morality-as-cooperation 'with a new questionnaire. Journal of Research in Personality, 78, 106-124.

Curry, O. S., Mullins, D. A., \& Whitehouse, H. (2019). Is It Good to Cooperate?: Testing the Theory of Morality-as-Cooperation in 60 Societies. Current Anthropology, 60(1), 4769.

Dawkins, M. B., Ting, F., Stavans, M., \& Baillargeon, R. (2019). Early moral cognition: A principle-based approach. In D. Poeppel, G. R. Mangun, \& M. S. Gazzaniga (Eds.), The cognitive neurosciences IV. Cambridge, MA: MIT Press.

DeFranza, D., Lindow, M., Harrison, K., Mishra, A., \& Mishra, H. (2020). Religion and reactance to COVID-19 mitigation guidelines. American Psychologist.

Elbert, S. P., \& Ots, P. (2018). Reading or listening to a gain-or loss-framed health message: Effects of message framing and communication mode in the context of fruit and vegetable intake. Journal of Health Communication, 23(6), 573-580.

Elster, A., \& Gelfand, M. J. (2021). When guiding principles do not guide: The moderating effects of cultural tightness on value-behavior links. Journal of Personality, 89(2), $325-337$.

Gallagher, K. M., \& Updegraff, J. A. (2012). Health Message Framing Effects on Attitudes, Intentions, and Behavior: A Meta-analytic Review. Annals of Behavioral Medicine, 43(1), 101-116.

Gelfand, M. J., Raver, J. L., Nishii, L., Leslie, L. M., Lun, J., Lim, B. C., ... \& Yamaguchi, S. (2011). Differences between tight and loose cultures: A 33-nation study. science, 332(6033), 1100-1104. 
Gifford, R., \& Comeau, L. A. (2011). Message framing influences perceived climate change competence, engagement, and behavioral intentions. Global Environmental Change, 21(4), 1301-1307.

Kenyon, C. (2020). Flattening-the-curve associated with reduced COVID-19 case fatality rates-an ecological analysis of 65 countries. Journal of Infection, 81(1), e98-e99.

Khan, S. R., \& Stagnaro, M. N. (2016). The influence of multiple group identities on moral foundations. Ethics \& Behavior, 26(3), 194-214.

Kraft-Todd, G. T., \& Rand, D. G. (2019). Rare and costly prosocial behaviors are perceived as heroic. Frontiers in psychology, 10, 234.

Legate, N., Nguyen, T. T., Weinstein, N., Moller, A. C., Legault, L., Maniaci, M. R., ... \& Chou, W. (2021). A Global Experiment on Motivating Social Distancing during the COVID-19 Pandemic. PsyArXiv.

Lunn, P. D., Timmons, S., Belton, C. A., Barjaková, M., Julienne, H., \& Lavin, C. (2020). Motivating social distancing during the Covid-19 pandemic: An online experiment. Social Science \& Medicine, 265, 113478.

Morrison, K. R., \& Johnson, C. S. (2011). When What You Have Is Who You Are: SelfUncertainty Leads Individualists to See Themselves in Their Possessions. Personality and Social Psychology Bulletin, 37(5), 639-651.

Nyhan, B., Reifler, J., Richey, S., \& Freed, G. L. (2014). Effective messages in vaccine promotion: a randomized trial. Pediatrics, 133(4), e835-e842.

Palomo-Vélez, G., Tybur, J. M., \& van Vugt, M. (2018). Unsustainable, unhealthy, or disgusting? Comparing different persuasive messages against meat consumption. Journal of Environmental Psychology, 58, 63-71. 
Pfattheicher, S., Nockur, L., Böhm, R., Sassenrath, C., \& Petersen, M. B. (2020). The emotional path to action: Empathy promotes physical distancing and wearing of face masks during the COVID-19 pandemic. Psychological Science, 31(11), 1363-1373.

Sarkar, K., Khajanchi, S., \& Nieto, J. J. (2020). Modeling and forecasting the COVID-19 pandemic in India. Chaos, Solitons, and Fractals, 139, 110049.

Soral, W., \& Bilewicz, M. (2021). The Politics of Vaccine Hesitancy: An Ideological DualProcess Approach. PsyArXiv.

Trivedi, P. (2020). India's Response to Coronavirus Pandemic: Nine Lessons for Effective Public Management. The American Review of Public Administration, 50(6-7), 725728.

World Health Organization. (2020). WHO Director-General's opening remarks at the Mission briefing on COVID-19-12 March 2020.

https://www.who.int/dg/speeches/detail/who-director-general-s-opening-remarks-atthe-mission-briefing-on-covid-19---12-march-2020

World Health Organization. (2021). Timeline: WHO's COVID-19 response. https://www.who.int/emergencies/diseases/novel-coronavirus-2019/interactivetimeline

Zakharin, M., Curry, O. S., Others in QIMR team, Martin, N. G., Lewis, G. J., \& Bates, T. C. (in preparation). Modular Morals: The Genetic Architecture of Morality as Cooperation. 